\title{
Strain Energy and Process Zone Based Fracture Characterization of a Novel Iron Carbonate Binding Material
}

\author{
Sumanta Das ${ }^{1}$, David Stone ${ }^{2}$, Barzin Mobasher ${ }^{3}$, Narayanan Neithalath $^{4, *}$ \\ ${ }^{1}$ Graduate Student, School of Sustainable Engineering and the Built Environment, Arizona State \\ University, Tempe, AZ, USA, e-mail: Sumanta.Das@asu.edu \\ ${ }^{2}$ CEO, Iron Shell LLC, Tucson, AZ, USA, e-mail: dajstone@gmail.com \\ ${ }^{3}$ Professor, School of Sustainable Engineering and the Built Environment, Arizona State University, \\ Tempe, AZ, USA, e-mail: barzin@asu.edu \\ 4,*Associate professor, School of Sustainable Engineering and the Built Environment, Arizona State \\ University, Tempe, AZ, USA, e-mail: Narayanan.Neithalath@asu.edu; (Corresponding author)
}

\begin{abstract}
The fracture behavior of a novel structural binder developed using carbonation of metallic iron powder is investigated using notched beams under three-point bending. The iron-based binder demonstrates significantly higher fracture energies compared to conventional ordinary portland cement binders in both unreinforced and glass fiber-reinforced states. The influence of metallic iron particle inclusions and the carbonate binder on the strain energy release rates $(R)$ and width of the fracture process zone (FPZ; which is the zone of strain localization at the tip of the crack) are evaluated and compared to that of portland cement-based binders. Tensile constitutive response of these binders is extracted using a crack-face bridging model. The control and fiber-reinforced iron-based binders demonstrate higher tensile strength and ultimate strain capacity as compared to conventional cementitious binders.
\end{abstract}

Keywords: Iron-based binder; Fracture process zone; Strain energy; R-curve; Tensile constitutive response 


\subsection{INTRODUCTION}

The past decade has seen the emergence of several alternatives to ordinary portland cement (OPC) for building and infrastructural construction. Most of the alternative material systems rely on partial replacement of OPC, at levels varying from $20 \%$ to $50 \%$ (mass-based), by industrial waste or by-product materials including fly ash and blast furnace slag [1-4]. Attempts to develop OPC-free binding systems also had varying degrees of success, as exemplified by the development of geopolymers that use fly ash or metakaolin as the primary source materials [5-7], or alkali-activated slags [8,9]. This paper reports on the properties of an OPC-free binding system, synthesized in an unconventional, yet highly sustainable manner. Here, metallic iron powder discarded as waste from industrial shot-blasting operations or foundries is carbonated at ambient temperature and pressure to yield a binder with beneficial properties. The added benefit of this approach is that $\mathrm{CO}_{2}$ emitted by an industrial operation such as a thermal power plant, or OPC production is sequestered permanently as carbonate in the binder material, thus ensuring that the material is carbon-negative.

A series of recent studies by the authors have described the material development, characterization, and properties of this novel binder [10-12]. Iron carbonate binders have been proportioned to attain compressive strengths in the range of 35-40 MPa, which is the upper limit of strength for more than $90 \%$ of OPC-based concretes used in practice. However, these matrices have been shown to demonstrate flexural strengths that are much higher than that of OPC-based systems. The iron-based binder system has also been shown to provide significantly higher fracture resistance than conventional OPC-based systems [12]. Detailed characterization of the material microstructure and pore structure to establish the factors that aid in these performance features, most notable of them being the presence of elastic, partially reacted or unreacted metallic particles show the effect of these particles on crack bridging and deflection [11]. The study presented here investigates the fundamental reasons for the beneficial fracture performance of these binder systems through the evaluation of the fracture process zone (FPZ), defined as a complex localized zone of energy dissipation around the propagating crack, containing the main crack as well as various branches of secondary and micro-cracks. The development of FPZ in the iron-based binder systems will be significantly different from those of OPC-based systems due to the differences in the material microstructure, especially the presence of iron particles. The influence of fiber reinforcement in these systems is also explored with respect to its synergistic action with the matrix response, which also is very different from those of OPC-based systems. 
By extending the evaluation of the fracture responses, the tensile constitutive behavior of the novel ironbased composite binder is extracted from resistance curves. The fracture energy is compared with the cohesive toughness of a unit tensile stress-crack width model $[13,14]$ to predict the tensile response. The differences in tensile response between OPC and iron-based binder systems are elucidated. Results are further investigated for the strain localization and crack propagation behavior of the novel binder using Digital Image Correlation (DIC). Adoption of suitable analytical models for tensile response, and comparison with OPC systems are expected to provide useful insights that aid in the development of guidelines for widespread use of this material.

\subsection{EXPERIMENTAL PROGRAM}

\subsection{Materials, Mixtures and Specimen Preparation}

Metallic iron powder with a median particle size of $19 \mu \mathrm{m}$ was used as the major starting material in this study. The iron powder was obtained from an industrial shot-blasting facility in Phoenix, AZ. The elongated and angular iron particles provide beneficial increased reactivity due to higher surface-to-volume ratio of the particles $[10,11]$. While the particle size distribution and shape of the iron powder is likely to influence the strength and fracture behavior, only one type of iron powder has been investigated in this study. The other additives used in the binder preparation included Class $\mathrm{F}$ fly ash and metakaolin conforming to ASTM C 618, and limestone powder (median particle size of $0.7 \mu \mathrm{m}$ ) conforming to ASTM C 568. Here fly ash was added as a silica source to potentially facilitate iron silicate formation [15-17] and limestone, to provide nucleation sites for reaction. Further details on mixture proportioning of this novel binder material can be found in [10]. In order to reduce the water demand and to maintain the cohesiveness of fresh mixture, a clay phase (metakaolin) was added. An organic reducing agent/chelating agent (oxalic acid in this case) was also added to facilitate better dissolution of the metallic iron and enhance its reactivity. Commercially available Type I/II OPC conforming to ASTM C150 was used to prepare conventional cement pastes to facilitate property comparisons with the novel binder. The chemical compositions of all the materials used here can be found in our previous publications [10-12]. The particle size distributions of the components of the blended mixtures are shown in Figure 1. Iron powder is coarser than all the other materials used. While the results may vary depending on fineness and content of iron powder, the basic trends of the results are expected to remain same. 


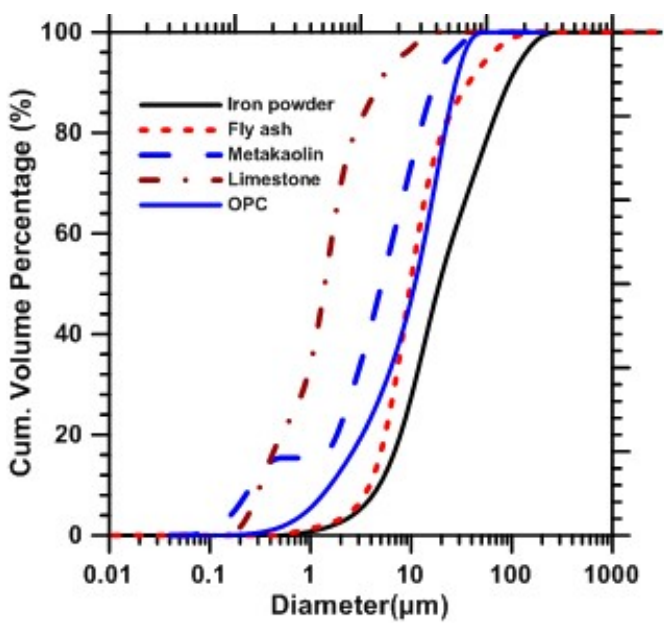

Figure 1: Particle size distribution of metallic iron powder, OPC, fly ash, metakaolin and limestone powder

The binder component used in this study includes $60 \%$ iron powder, $20 \%$ fly ash, $8 \%$ limestone, $10 \%$ metakaolin and $2 \%$ oxalic acid by mass. These proportions were arrived at based on strength and porosity of several trial mixtures [10]. The mixing procedure involves initial dry mixing of all the constituents followed by addition of water to form a uniform cohesive mixture. A mass-based water-to-powder ratio of 0.24 was sufficient to provide a cohesive and uniform mixture. Since water is not chemically combined in the reaction products, it is primarily used from a rheological perspective.

Prismatic beams of size $127 \mathrm{~mm}$ (length) $\times 25.4 \mathrm{~mm}$ (depth) $\times 25.4 \mathrm{~mm}$ (width) were prepared in polycarbonate molds and the samples were placed inside clear plastic bags in a $100 \% \mathrm{CO}_{2}$ environment at normal temperature and pressure for 24 hours. Since the beams are to be tested under notched conditions, a brass plate of $1 \mathrm{~mm}$ thickness with rounded edge ( $0.5 \mathrm{~mm}$ diameter) was attached to the top of the mold to create the notch. The plate was removed after three hours of casting. This method enables the consistent creation of a notch of $1 \mathrm{~mm}$ width with a rounded tip of $0.5 \mathrm{~mm}$ radius. The beams were then demolded and kept in a $100 \% \mathrm{CO}_{2}$ environment for 5 more days. The bags were refilled with $\mathrm{CO}_{2}$ every 12 hours in order to maintain $\mathrm{CO}_{2}$-saturation. After carbonation, the samples were placed in air for 4 days for evaporation of moisture from the samples. These carbonation and air-curing durations were also arrived at based on a previous study [10]. For comparison purpose, companion OPC beams of same size were prepared using a water-to-cement ratio $(\mathrm{w} / \mathrm{c})$ of 0.40 which is common for moderate-strength concretes for infrastructural applications. The beams were demolded after 24 hours and placed in a moist chamber $\left(>98 \% \mathrm{RH}\right.$ and $23 \pm 2^{\circ} \mathrm{C}$ ) for a total of 28 days. The fiber-reinforced binders were prepared by adding $0.5 \%$ and $1.0 \%$ alkali-resistant glass fibers ( $25 \mu \mathrm{m}$ diameter and $10 \mathrm{~mm}$ long) by volume to the 
blends while mixing. The fiber reinforced iron-based and the OPC binders were cured in the same way as their non-reinforced counterparts.

\subsection{Cyclic Three-point Bending Test for Evaluation of Fracture Properties}

Three-point bending test was performed on notched beams (notch depth-to-beam depth ratio of 0.15) using a closed-loop flexural testing setup. Four replicate beams were tested for each case. Several loadingunloading cycles were employed, and the unloading compliance during each cycle was used to determine the strain energy release rate and fracture resistance. Crack mouth opening displacement (CMOD), measured using a clip gauge, was used as the controlling signal during loading cycles whereas loadcontrolled mode was employed during unloading cycles. The tests were run monotonically under CMODcontrolled mode for evaluation of the strain localization zone through non-contact measurement using digital image correlation (DIC).

\subsection{Digital Image Correlation (DIC) for Evaluation of Fracture Process Zone}

DIC is a non-contact optical speckle-tracking measurement method to obtain full-field surface displacements through successive post-processing of digital images taken at specific time intervals. The principle and applications of DIC are well documented [12,18-26]. The surfaces of the beams were speckled to create random patterns. A CCD (Charged-Couple Device) camera was used to record images every 5 seconds. After collection of all the images, a suitable region of interest (ROI) was chosen for analysis, as shown in Figure 2(a). The 2D displacement fields are obtained from correlation between the subsets of images from the deformed and undeformed state as shown in Figure 2(b). The horizontal (u) and vertical ( $v$ ) displacement fields in the surface analysis region are then computed by minimization of the correlation coefficient $(C)[23,25]$. The image processing and analysis operations were carried out using a commercial software (VIC-2D ${ }^{\mathrm{TM}}$ ).

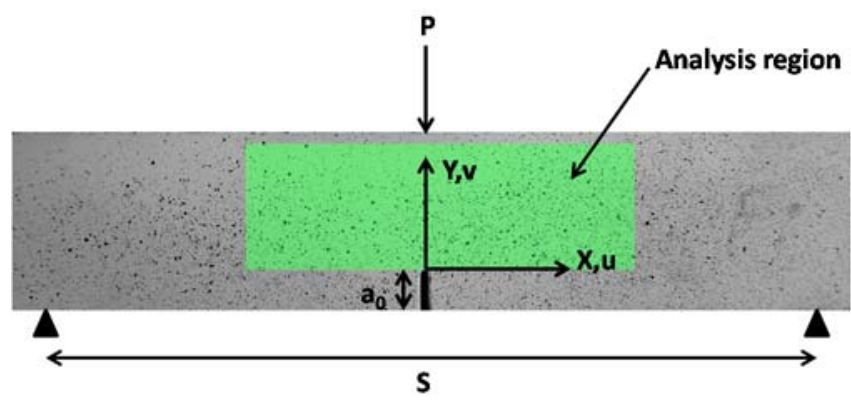

(a)

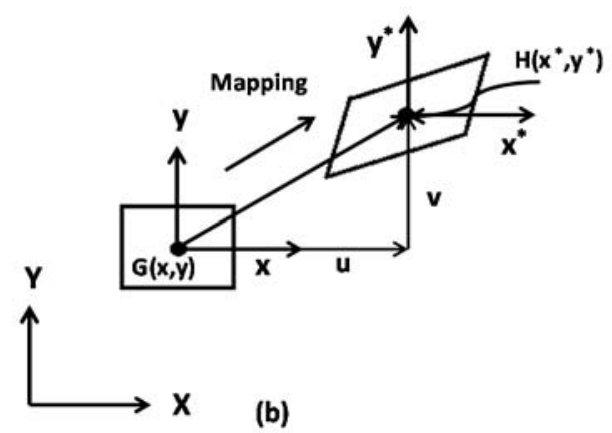

(b) 
Figure 2: (a) Three-point bend specimen showing the analysis region for displacement field mapping, and (b) schematic of mapping of points in DIC

The Lagrangian strain fields are then obtained from the displacement fields as given in Equations $1(a-c)$ [26-28]:

$$
\begin{gathered}
e_{x x}=\frac{\partial u}{\partial x}+\frac{1}{2}\left[\left(\frac{\partial u}{\partial x}\right)^{2}+\left(\frac{\partial v}{\partial x}\right)^{2}\right] \\
e_{y y}=\frac{\partial v}{\partial y}+\frac{1}{2}\left[\left(\frac{\partial u}{\partial y}\right)^{2}+\left(\frac{\partial v}{\partial y}\right)^{2}\right] \\
e_{x y}=\frac{1}{2}\left[\frac{\partial u}{\partial y}+\frac{\partial v}{\partial x}\right]+\frac{1}{2}\left[\left(\frac{\partial u}{\partial x} \frac{\partial u}{\partial y}\right)+\left(\frac{\partial v}{\partial x} \frac{\partial v}{\partial y}\right)\right]
\end{gathered}
$$

While the crack tip opening displacement (CTOD) and the crack extension (corresponding to the load and CMOD pertaining to that time step) can be quantified from the results of u-displacement fields [12,2426], the in-plane Lagrangian strain field calculated from the displacement fields, particularly its component $\mathrm{e}_{\mathrm{xx}}$ that corresponds to the crack opening direction, provides important information on strain localization at the tip of the crack.

\subsection{RESULTS AND DISCUSSIONS}

\subsection{Cyclic load-CMOD response of notched beams}

The representative load-CMOD responses of control and fiber reinforced iron-based and OPC binders are shown in Figures 3(a) and (b) respectively. Multiple loading-unloading cycles are employed in order to determine compliance based resistance $(R)$ curves which are used to determine the tensile stress-strain responses discussed in detail later. A preliminary evaluation of flexural load-CMOD data indicates a significant improvement in the flexural strength and post-peak response that is clearly visible in Figure 3(a) for the iron carbonate binder when $1 \%$ glass fiber by volume is added. Figure 3(c) shows the peak flexural loads for OPC and iron-based binder at different fiber loadings. The control iron-based binder shows significantly higher peak flexural load as compares to OPC paste (Figure 3(b)), which can be attributed to presence of unreacted metallic iron particle inclusions surrounded by strong carbonate matrix in the iron-based binder [11,12]. The peak flexural load increases with incorporation of fiber in both the systems but the iron-based binder shows more pronounced increase in flexural peak load due to 
the synergistic effect of the iron carbonate matrix (including the unreacted iron particles) and the fibers on the flexural response, explored in detail elsewhere [12]. Figure 3(d) shows the total fracture energy, calculated using Hillerborg's work-of-fracture method as shown in Equation 2 [26,29], for the OPC and iron-based novel binder.

$$
G_{F}=\frac{W_{0}+2 P_{W} \delta_{0}}{\left(D-a_{0}\right) t}
$$

In Equation 2, $\mathrm{W}_{0}$ is the area under the load-CMOD curve, $\delta_{0}$ is the CMOD at failure, $\mathrm{D}$ is depth of the beam, $a_{0}$ is the notch depth, $t$ is the beam thickness, and $P_{w}$ is the self-weight of the beam.
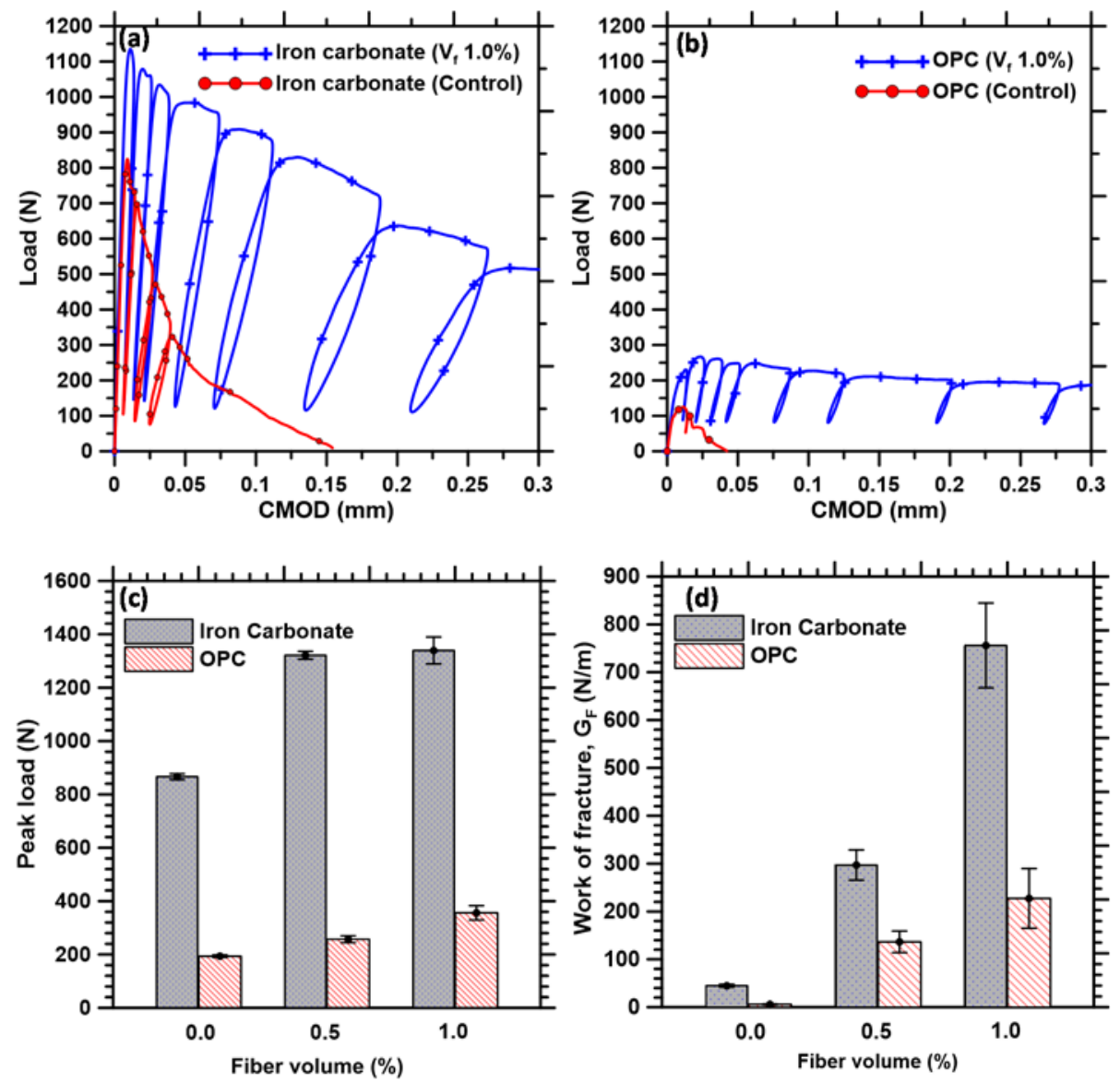

Figure 3: Representative Load-CMOD responses for (a) iron carbonate binder and (b) OPC with and without fiber reinforcement, (c) peak flexural loads for the OPC and iron carbonate binders, and (d) total fracture energy of OPC and iron carbonate binders used in this study. The error bars represent one standard deviation of peak load or fracture energy obtained from four replicate specimens. 
Total fracture energy, which is a reflection of post-peak performance and crack tolerance of materials, is found to be significantly higher for the iron-based binder than OPC in both control and fiber-reinforced states for the reasons explained earlier. For instance, at $1 \%$ fiber volume fraction, the fracture energy is about 4 times higher for the iron-based binder. The peak loads and fracture energies shown here provide an indication of the performance improvement attainable by the novel iron carbonate binder system as compared to the conventional OPC-based systems.

\subsection{Strain energy release rates (R-curves)}

While the superior performance of iron-based binder as compared to OPC is established in a recent publication [12] using a two-parameter fracture model, this section shows the strain energy release rates used in the context of R-Curves for the determination of tensile constitutive response using strain energybased inverse analysis.

Compliance-based determination of $[12,25,30,31]$ strain energy release rate is based on the assumption that stable crack propagation leads to an increase in specimen compliance. The elastic component is calculated from the unloading compliance whereas the inelastic CMOD is used to calculate the component of dissipated energy. Unloading compliance is determined as the slope of fit line to the linear part of unloading cycle whereas the residual CMOD upon unloading (unloading to approximately $10 \%$ of the capacity to ensure maintenance of contact between the clip gauge and the specimen) in each cycle is quantified as the inelastic or nonrecoverable CMOD. The total strain energy release rate $\left(G_{R}\right)$ is given as:

$$
G_{R}=G_{\text {elastic }}+G_{\text {inelastic }}=\frac{P^{2}}{2 t} \frac{\partial C}{\partial a}+\frac{P}{2 t} \frac{\partial\left(C M O D_{\text {inelastic }}\right)}{\partial a}
$$

Here ' $C$ ' is the unloading compliance, ' $t$ ' is the thickness of the specimen, ' $P$ ' is the applied load, and ' $a$ ' is the effective crack length calculated by substituting values of unloading compliance in a nonlinear equation [25]. The unloading compliance and inelastic CMOD is expressed as a function of effective crack length using polynomial fit and the functions are differentiated with respect to the crack length (a) to obtain the different terms in Equation [3].

R-curves for the OPC and iron-based binders are shown in Figure 4(a). In the unreinforced state, the OPC system shows very little crack growth resistance, consistent with the brittle nature of a hydrated OPC paste, whereas the iron-based binder exhibits significantly higher resistance. Incorporation of fibers improves the resistance for the OPC matrix although the $\mathrm{R}$ values are still lower as compared to the fiberreinforced iron-based binder for the reasons explained earlier. Figures $4(b)$ and (c) show the individual 
contributions of elastic and inelastic components to the total strain energy release rates for the different binders. The elastic component of the strain energy release rate can be attributed to incremental crack growth whereas the inelastic component arises from effects such as frictional loss, and permanent deformation caused due to crack-opening $[25,26]$. The elastic component is found to be dominant in the iron-based binder systems, whether reinforced or not, whereas the inelastic strain energy release rate, i.e., the result of energy dissipation by crack opening, is dominant for the OPC systems. The higher elastic strain energy release rate in iron-based binder is attributed to the presence of unreacted, elastic, elongated iron particles in the carbonate matrix. On the other hand, the OPC paste, because of its brittleness, shows almost negligible contribution from the matrix and almost all the resistance is provided by the fibers (inelastic resistance). The maximum values of strain energy release rates are used in an inverse analysis procedure (Section 3.4) to calculate the tensile constitutive response of OPC and ironbased binding systems. In the case of iron-based binder, the presence of a stronger ductile matrix phase (unreacted iron particles surrounded by the carbonate reaction products) will likely enhance the tensile strength, as will be elaborated in detail later.
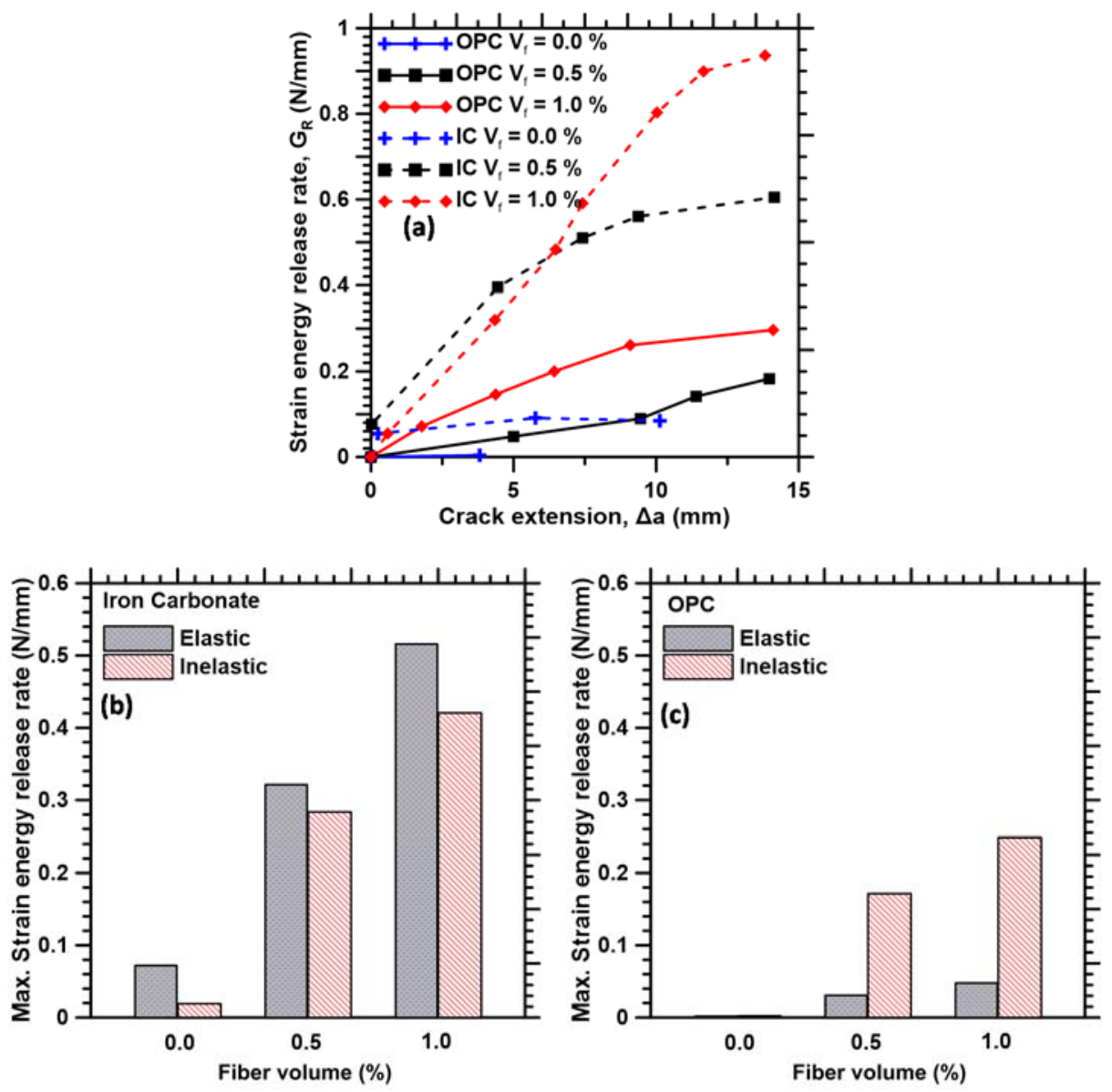
Figure 4: (a) Total strain energy release rates for the unreinforced and fiber reinforced iron-based and OPC binder systems; (b) and (c) elastic and inelastic components of maximum strain energy release rates for iron-based binder and OPC paste respectively.

\subsection{Characterization of Fracture Process zone (FPZ) in the novel binder systems}

This section examines the fracture process zone defined as the zone of micro-crack formation, coalescence, and bridging ahead of the crack tip, in the selected binder systems to elucidate the differences in the crack propagation mechanism influenced by the matrix type (OPC or iron-based) and the presence of fiber reinforcement. The fundamentally different fracture response demonstrated by the iron carbonate binder is explained through a detailed characterization of FPZ.

\subsubsection{Determination of width and length of FPZ}

In this paper, the measurements perpendicular to the direction of crack growth correspond to the 'width' and the measurements along the direction of crack growth correspond to the "length" of the zone of strain localization. The width of the localized region can be expected to provide useful information on the fracture mechanism of the material. In the present study, the width of the localized region is used to compare the fracture characteristics of OPC and iron-based binder in both control and fiber-reinforced states. In addition, the width of localized zone is used as a "gage-length" for the determination of postpeak tensile strain. The process of determination of width of localized region using the Lagrangian strain profiles from DIC is explained below.

Figure 5(a) shows a monotonic load-CMOD response of unreinforced iron-based binder. Figure 5(b) shows a typical surface strain field $\left(e_{x x}\right)$, calculated from the surface displacement field at $95 \%$ of the peak load in the post-peak regime from which the localized strain concentration above the notch can be identified easily. The reason for selection of this load level to characterize the FPZ of cementitious materials has been stated in a recent publication [25]. It has also been noted that the width of the FPZ is fully developed at this load level beyond which the increase in CMOD does not result in significant changes in the width. Figure 5(c) shows the strain profile at a height of $2.5 \mathrm{~mm}$ above the notch along the horizontal direction. In order to determine the width of the localized zone, the surface strain profile (at a certain height above the notch) is fitted as a normal distribution function using $\sigma$ as a measure of the spread of the strainlocalized zone as shown in Equation 4.

$$
f(x, \sigma)=\frac{1}{\sigma \sqrt{2 \pi}} e^{-\frac{1}{2}\left(\frac{x}{\sigma}\right)^{2}}
$$


Considering that a normal distribution curve truly represents the strain profile in the X-direction, the FPZ width can be considered to be equal to $4 \sigma$ since $95 \%$ of the values of the normal distribution function are within $\pm 2 \sigma$ of the mean value. A similar approach has been used elsewhere $[26,32,33]$. The FPZ widths reported here are used only for comparison since it is highly influenced by the image resolution; a higher image resolution resulting in a smaller FPZ width [32]. The length of FPZ is measured as the extent of strain localization in the crack extension direction. The localized zone terminates when the strain along the crack extension direction is lower than $20 \%$ of the strain at the tip of the notch.

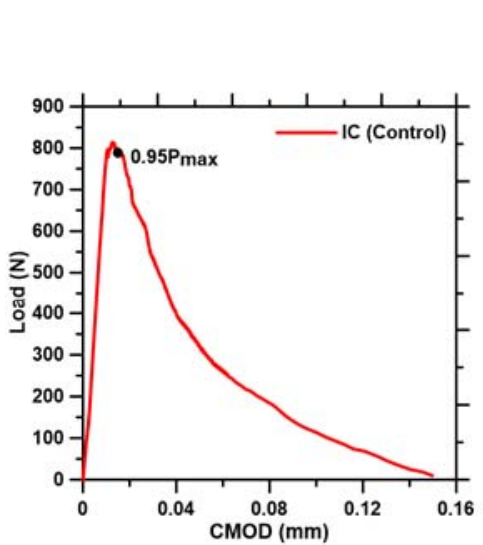

(a)

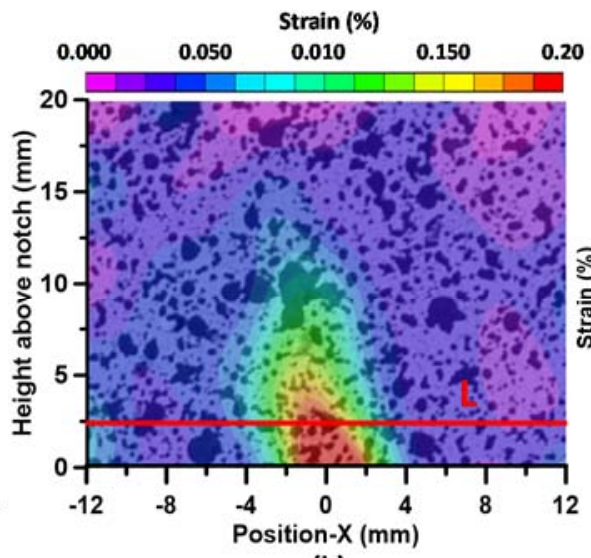

(b)

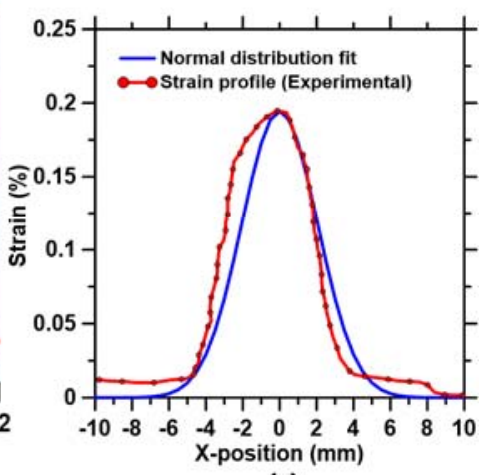

(c)

Figure 5: (a) Monotonic load-CMOD response of unreinforced iron carbonate binder; (b) Localized zone above the notch obtained from DIC; and (c) horizontal normal strain $\left(\varepsilon_{x x}\right)$ profile across the localized zone for the iron-based binder at the location denoted by $L$ in (b).

\subsubsection{FPZ features and the influence of matrix type and the presence of fiber reinforcement}

Figures $6(a)$ and (b) show the FPZ for the unreinforced OPC and iron carbonate binders. A qualitative indication of FPZ width is also obtained from these figures. The iron-based binder shows a wider FPZ. Results extracted at $95 \%$ of the peak load in the post-peak region indicate a decrease in the width of FPZ with an increase in distance from the crack (notch) tip for both the binders. Figure 6(c) shows that rate of reduction of FPZ width is also very similar for both the unreinforced binders. Figures 7(a) and (b) show the FPZ for the fiber-reinforced ( $1 \%$ by volume) OPC and iron carbonate binders. An observation of the local strain levels show higher strains in the fiber-reinforced systems as compared to unreinforced pastes shown in Figure 6. This can be attributed to the increased strain capacity of the fiber-reinforced systems. Also, the strain in the iron-based binder is slightly lower than that of the corresponding OPC system due to the increased spread of FPZ in the former case as can be noticed from Figures 6 and 7. Another 
distinctive feature in the fiber-reinforced binders is the rather uniform localized strain distribution as a function of distance above the notch tip as seen in Figure $7(c)$, attributable to the fiber bridging effect.

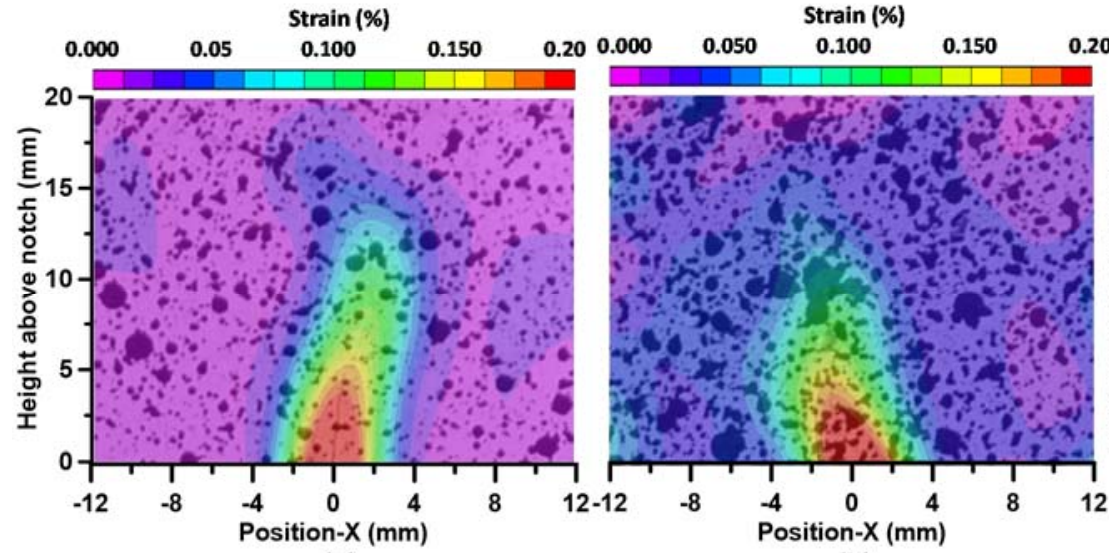

(a)

(b)

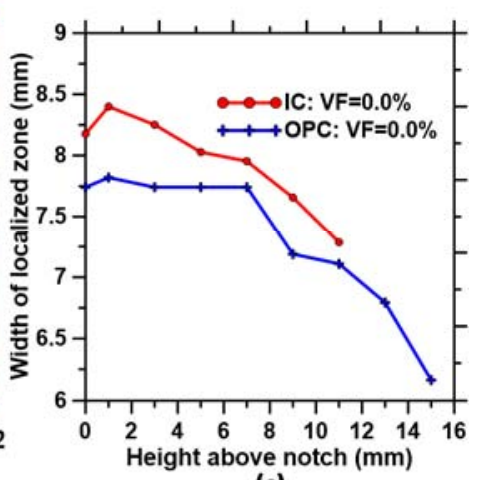

(c)

Figure 6: (a) and (b) Strain localization above the tip of the notch in unreinforced OPC and iron-based binders respectively, and (c) width of FPZ as a function of distance from the notch tip for both the binders. The data is for $95 \%$ of the peak load in the post-peak region.

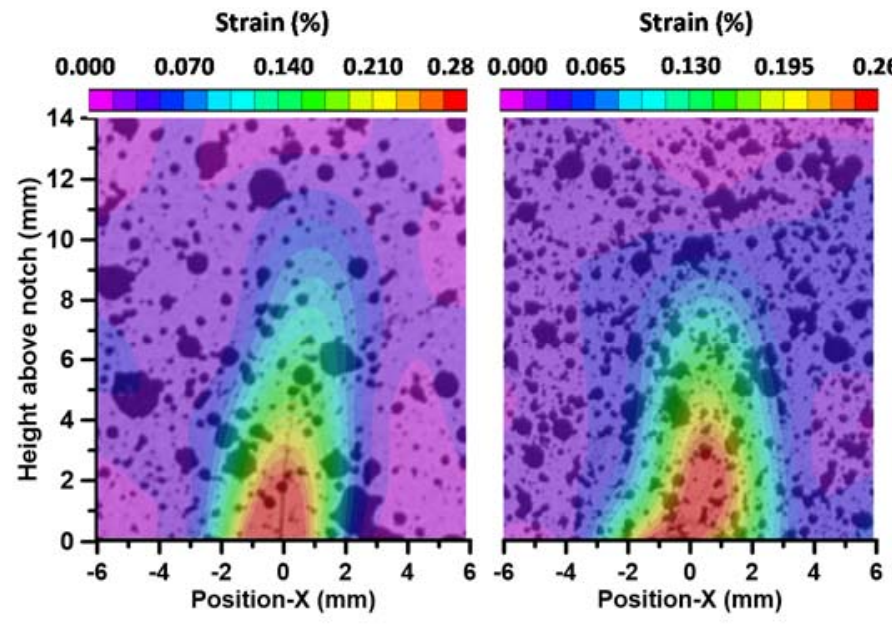

(a)

(b)

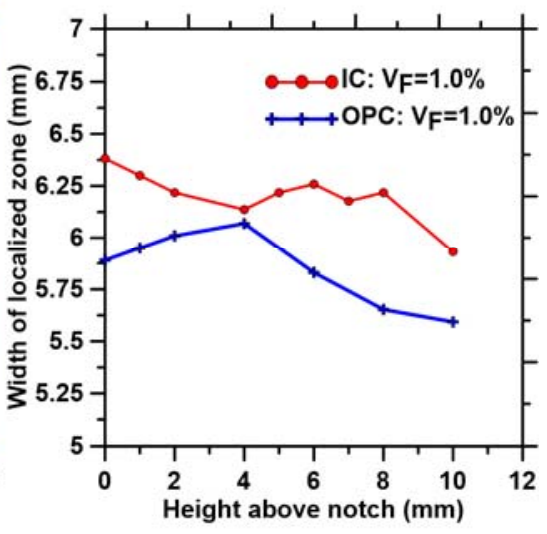

(c)

Figure 7: (a) and (b) Strain localization above the tip of the notch in fiber-reinforced reinforced OPC and iron-based binders respectively, and (c) width of FPZ as a function of distance from the notch tip for both the binders. The data is for $95 \%$ of the peak load in the post-peak region.

The quantified average values of FPZ length, width, and area in both the OPC and iron-based (unreinforced and fiber-reinforced) systems are shown in Figures 8(a), (b) and (c) respectively. The FPZ width profiles are numerically integrated with respect to the height above the notch to quantify the area of FPZ. The width and area of FPZ for both the unreinforced and reinforced iron-based binders are higher than OPC 
binder whereas the length of FPZ is the same for both binder systems. The higher width of FPZ in the ironbased system can also be related to the higher inelastic strain energy release rates as shown earlier. On the other hand, the FPZ lengths in iron-based and OPC binders corresponding to $95 \%$ of the peak load in the post-peak regime are almost similar although the iron-based binder showed a higher elastic strain energy release rate, which is a measure of resistance against incremental crack-growth. This behavior can be attributed to the increased load carrying capacity of the iron-based binder (four-to-six times stronger than the OPC binder - See Figure 3) being the dominant contributor to strain energy release rates.

The length, width and area of FPZ are lower in fiber-reinforced binders compared to the unreinforced binders. Incorporation of fibers reduces strain localization as the fibers transmit the load across the cracks and resist crack-opening and extension. Furthermore, the fiber-reinforced systems exhibit higher inelastic strain energy release rates as compared to the unreinforced systems even when the spread of localized region is reduced. Higher strain energy release rate in the fiber-reinforced systems is facilitated not just through the spread of the zone of micro-cracking in the matrix, but also through the increased strain capacity in the systems. The ultimate tensile strains extracted from an inverse analysis is shown in a later section to prove this point. The overall inelastic strain energy dissipation in unreinforced systems is likely to be mainly contributed by mechanisms such as spread of the zone of strain-localization through microcracking. However, the fiber reinforced systems are expected to resist the spread of the zone of microcracking through crack-bridging effect, thereby facilitating relatively uniform spread of FPZ above the notch. Similarly, the elastic component of strain energy release rate (Figure 4(b)) is found to be the dominant contributor to the overall increase in strain energy release rate of iron-based binders containing fiber reinforcement in spite of reduction in the FPZ length. This is attributed to the elastic component of strain energy release rate being proportional to square of the load term (Equation 3), and thus the higher load carrying capacity (Figure 3(b)) of the fiber-reinforced iron-based binders is more prominent than the FPZ length on their relative influences on elastic strain energy release rates. This helps better understand the relative influences of the matrix type and the fiber on the strain localization and crack propagation mechanisms in these binder systems. 

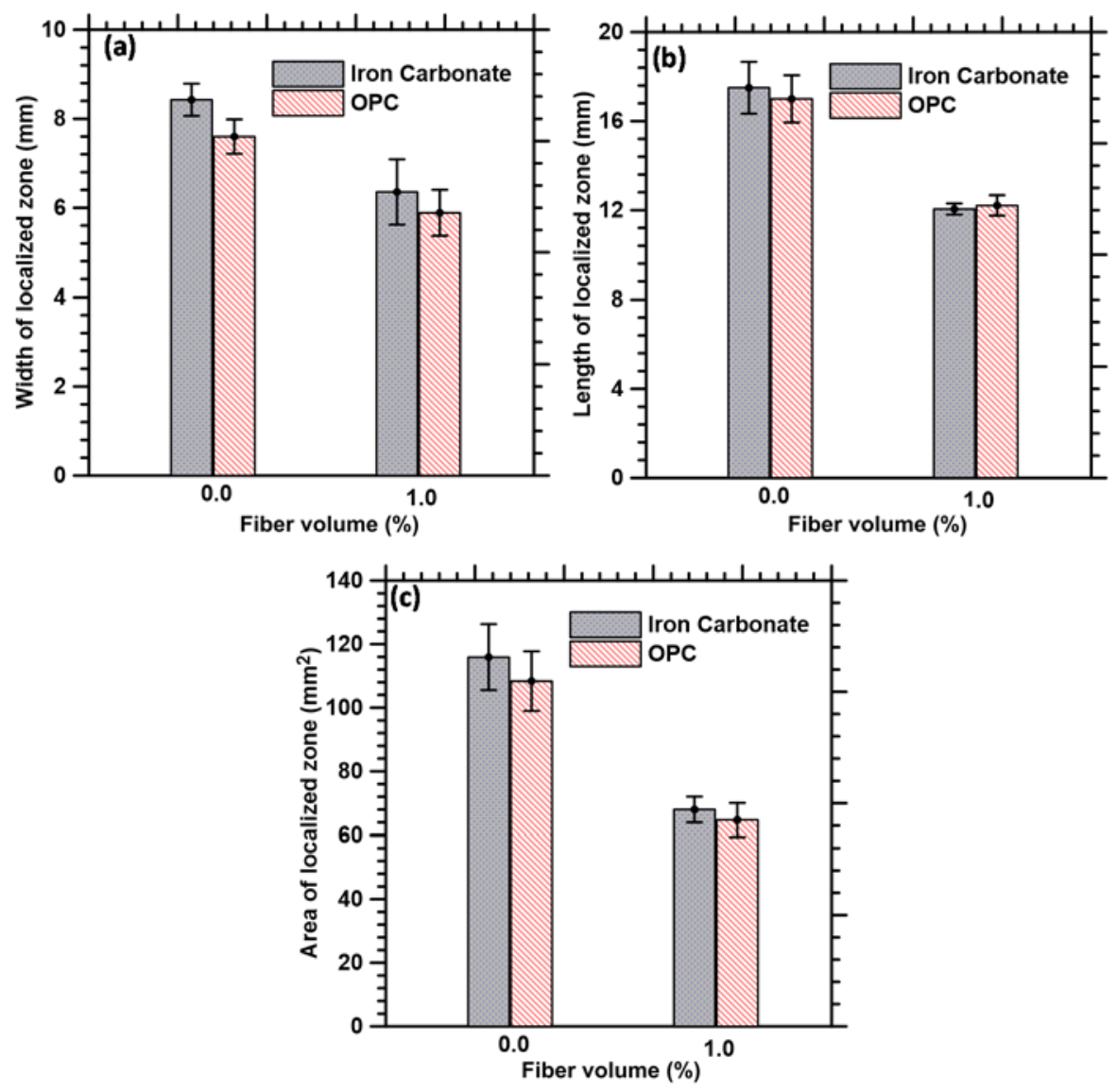

Figure 8: Comparison of: (a) width of FPZ, $7 \mathrm{~mm}$ above notch; (b) length of FPZ, and (c) area of FPZ. For both the binder types, the FPZ characteristics are determined at $95 \%$ of the peak load in the post-peak regime.

Figures 9(a) and (b) depict the variation in the width of FPZ with increase in CMOD and crack extension respectively. Both the binders exhibit initiation of localized zone at similar values of CMOD. Full width of FPZ develops at a lower value of CMOD for the unreinforced OPC binder as compared to the iron-based binder, signifying its brittleness which is also reflected in the rapid extension of crack (Figure 9(b)) after the formation of FPZ. Iron-based binders are more resistant to cracking compared to the OPC binders since at any given FPZ width, the crack extension is always lower. The crack growth resistance of ironbased binders due to is unreacted iron particulate inclusions in the strong carbonate matrix [12]. Figure 9(c) shows the variation in FPZ width with applied load. The general trends suggest that the FPZ width increases initially as the load increases and the full width of process zone is developed at or close to the peak load, beyond which the width remains almost constant as the crack propagates. Superior performance of iron-based binders is reflected in the form of significantly lower rates of increase in FPZ width with increase in load. 

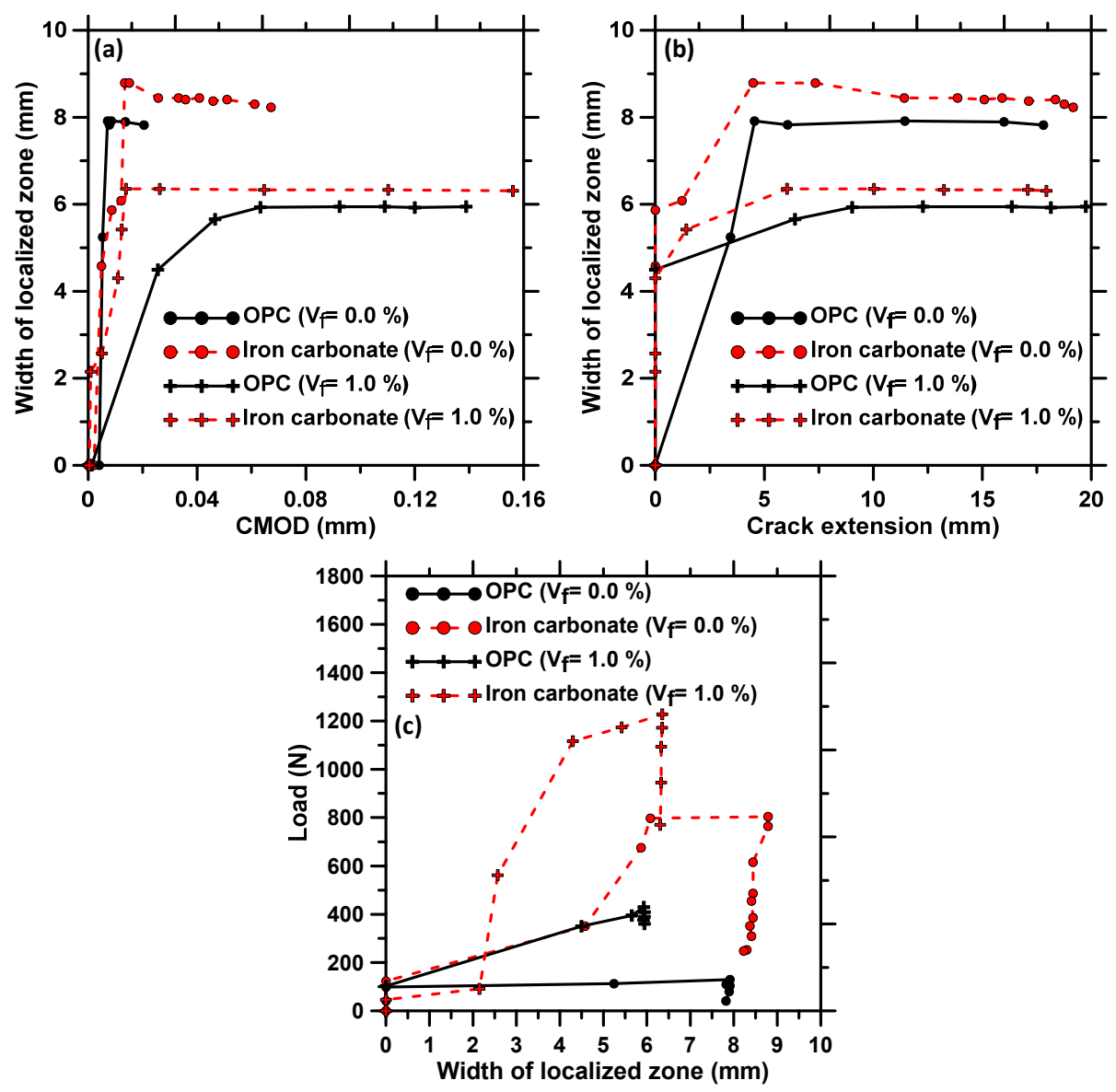

Figure 9: Variation of width of FPZ with changes in: (a) CMOD, (b) crack extension, and (c) load.

\subsection{Extracting the tensile constitutive response from strain energy release rates}

The previous sections on strain energy release rates and quantification of FPZ have indicated the fracture performance of unreinforced and fiber-reinforced novel iron-based binders vis-à-vis OPC binders. In this section, the tensile constitutive relationships for these binders are developed as they better represent the material behavior than the flexural response which fails to account for the presence and growth of cracks in the pre-peak regime. The tensile constitutive response is back-calculated from maximum strain energy release rates through a potential energy approach using a crack-face bridging model $[13,14]$. It has been shown that this method produces comparable tensile stress-strain responses as derived from other wellknown methods such as moment-curvature based inverse analysis approach [26]. 


\subsubsection{Crack-face bridging model and contribution to toughening due to closing pressure}

Toughening in quasi brittle materials occurs by several micro-fracture mechanisms at the FPZ ahead of observable crack-tip and at crack-face contact regions. Among them, crack-face bridging is a dominant mechanism that contributes to rising crack growth resistance $(R)$ curves [30,34]. In this study, a model for crack-face bridging [13] is employed to determine the tensile stress-strain response as a power function expression [13,14] for stress-crack width relationship as shown in Figure 10.

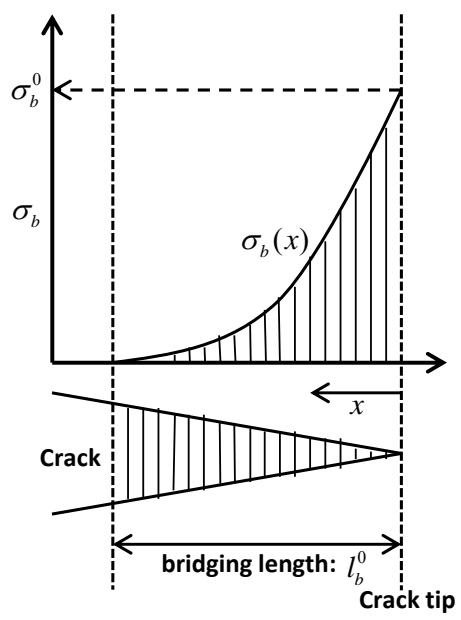

(a)

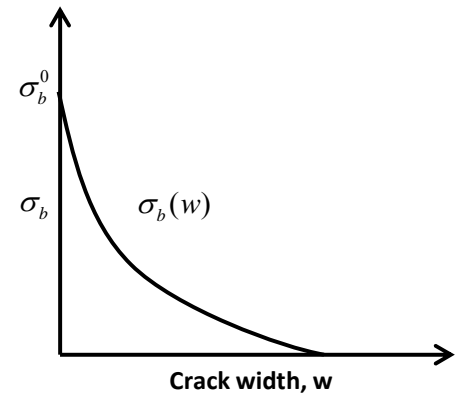

(b)

Figure 10: (a) Cohesive stress distribution for a unit bridging stress at $a=a_{c}$ when the FPZ length is fully developed, and (b) stress-crack width relationship [13]

$$
\begin{gathered}
\sigma_{b}\left(w_{b}\right)=\sigma_{b}^{0}\left(1-\frac{w_{b}}{w_{b}^{0}}\right)^{n} \\
w_{b}(x)=w_{b}^{0}\left(\frac{x}{l_{b}^{0}}\right)^{q}
\end{gathered}
$$

Here $\sigma_{b}$ is the crack-face bridging stress, $w_{b}$ is the crack-opening displacement, $\sigma_{b}{ }^{0}$ is the critical bridging stress, $w_{b}{ }^{0}$ is the maximum crack opening displacement, $l_{b}{ }^{0}$ is the bridging zone length and ' $q$ ' and ' $n$ ' are the two constants reflecting the shape and distribution of the crack-face bridging tractions. The values of ' $q$ ' and ' $n$ ' are taken as 0.6 and 3.0 respectively based on the work of Suzuki and Sakai [13]. The cohesive toughness, computed using potential energy approach by integrating the toughening through crack-face bridging over the entire bridging length, is given as [14,35]:

$$
\Delta G=2 \int_{0}^{l_{b}} \sigma_{b}(w) \cdot\left(\frac{\partial w}{\partial x}\right) d x
$$


When $\mathrm{a}=\mathrm{a}_{\mathrm{c}}$, cohesive toughness can be computed from experimental analysis using maximum strain energy release rates. The parameters required for the integration in Equation 6 include $l_{b}{ }^{0}$ which is the bridging zone length calculated as: $l_{b}{ }^{0}=\Delta a_{c}=\left(a_{c}-a_{0}\right)$, and $w_{b}{ }^{0}$ which is the maximum crack-opening displacement. The only unknown parameter is the critical bridging stress $\sigma_{b}{ }^{0}$ or tensile strength. Hence the right hand side of Equation 6 can be equated to the experimentally determined cohesive toughness based on strain energy release rates to solve for tensile strength. This inverse analysis procedure is described in detail in [14].

The tensile stress-strain response can be thus calculated assuming elastic response in the pre-peak region and using the concept of a characteristic length in the post-peak region. The post-peak tensile strains (beyond the elastic regime) are obtained by implementing an average value of crack opening displacement $\left(w_{b}\right)$ distributed over a gage-length. The gage-length is quantified using digital image correlation as the average width of strain localization along the height of the beam, at $95 \%$ of the peak load in the post-peak regime, since the width remains almost constant beyond that loading state.

$$
\begin{array}{ll}
\varepsilon_{t}=\frac{\sigma_{t}}{E} & \text { (Elastic region: pre-peak) } \\
\varepsilon_{t}=\frac{w_{b}}{L_{g}} & \text { (Post-peak region) }
\end{array}
$$

\subsubsection{Comparison of tensile behavior of control and glass fiber-reinforced OPC and iron-based novel binder}

Figure 11(a) shows the back-calculated tensile stress-strain relationships for the unreinforced OPC and iron-based binders. The iron carbonate binder has a substantially higher tensile strength, tensile modulus, and ultimate tensile strain as compared to to the OPC binder because of the stronger matrix with unreacted ductile metallic iron inclusions which facilitates crack bridging and/or deflection through closing pressure on the crack. The elastic incompatibility and debonding between metallic particlecarbonate matrix interface contributes to crack deflection as explained in detail elsewhere [12]. The effect of glass fibers on the extracted tensile stress-strain response of these systems are shown in Figure 11(b). Incorporation of fibers increases the tensile strength and ultimate tensile strain in both systems although the elastic modulus remain relatively unchanged. The ultimate tensile strains are improved by an order of magntiude or more with the incorporation of fibers. The fiber-reinforced iron-based binder shows significantly higher tensile strength and ultimate tensile strain as compared to fiber-reinforced OPC 
binder. The performance of the matrix is further augmented by the crack-bridging effect of fibers, wheareas in OPC binder, the brittle matrix fails abruptly and the load is completely carried by the fibers resulting in significantly lower tensile strength and ductility.
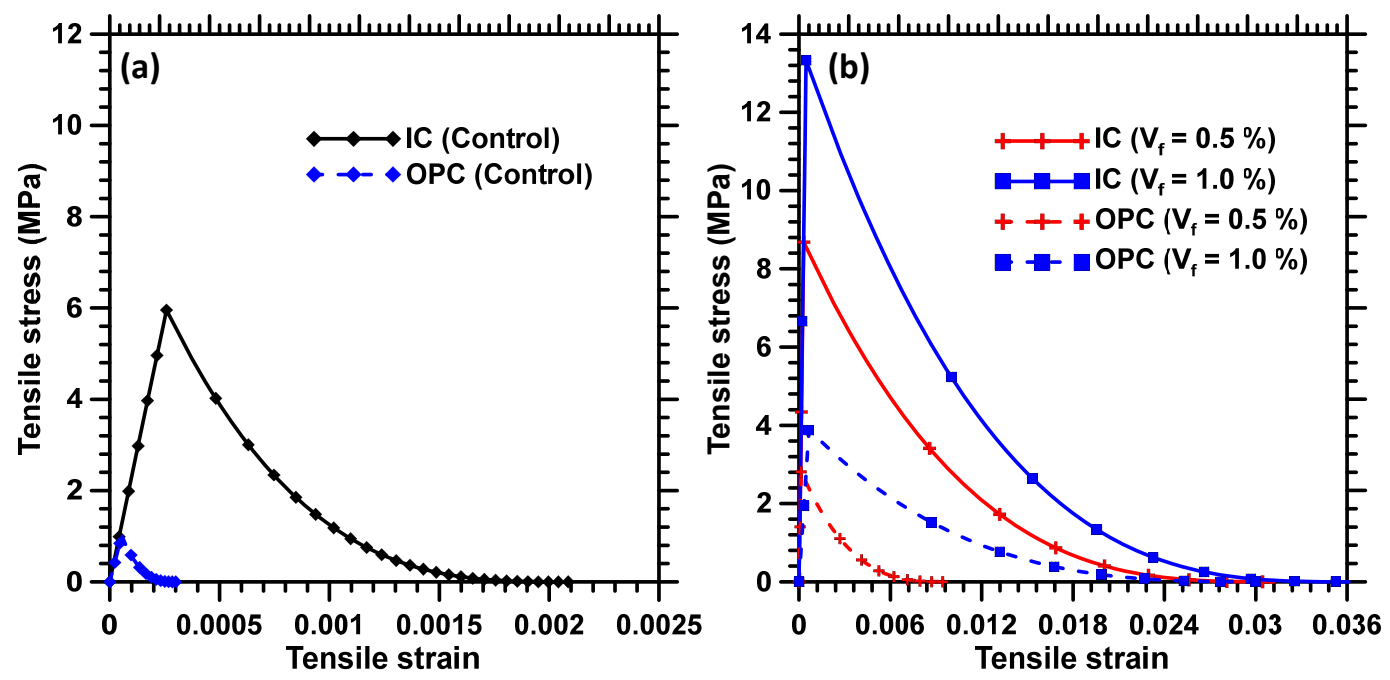

Figure 11: Tensile stress-strain response for OPC and iron carbonate binder: (a) unreinforced binder, (b) fiber-reinforced composites. Note that the strain axes scales are different.

Figure 12(a) shows the extracted tensile strength of these binders at different fiber loading levels. Tensile strength increases with increase in fiber volume fractions for both the systems with a more pronounced trend in the iron-based binder. The unreinforced iron-based binder is 5-6 times stronger than the OPC binder, in line with the results in [12]. Similar trends are observed for the fiber-reinforced systems as well. The ultimate tensile strains (Figure 12(b)) for the iron-based binder are significantly higher as compared to OPC due to better post-peak performance of iron-based systems. Higher tensile toughness of ironbased binder, shown in Figure 12(c) supports the observation of higher FPZ area as compared to the OPC binder in the unreinforced state (Figure 8(c)) whereas the significantly higher tensile toughness of the fiber-reinforced iron-based binder resulted in a decrease in the FPZ area. The latter signifies the dominant effect of crack-bridging mechanism in the fiber-reinforced binder systems. Fiber volume fraction does not seem to impact the elastic modulus of either system as the fibers mainly contribute to the post-peak response. Iron-based binders exhibit higher value of elastic modulus as compared to that of OPC-based binders which can be attributed to the presence metallic iron particulate inclusions. 


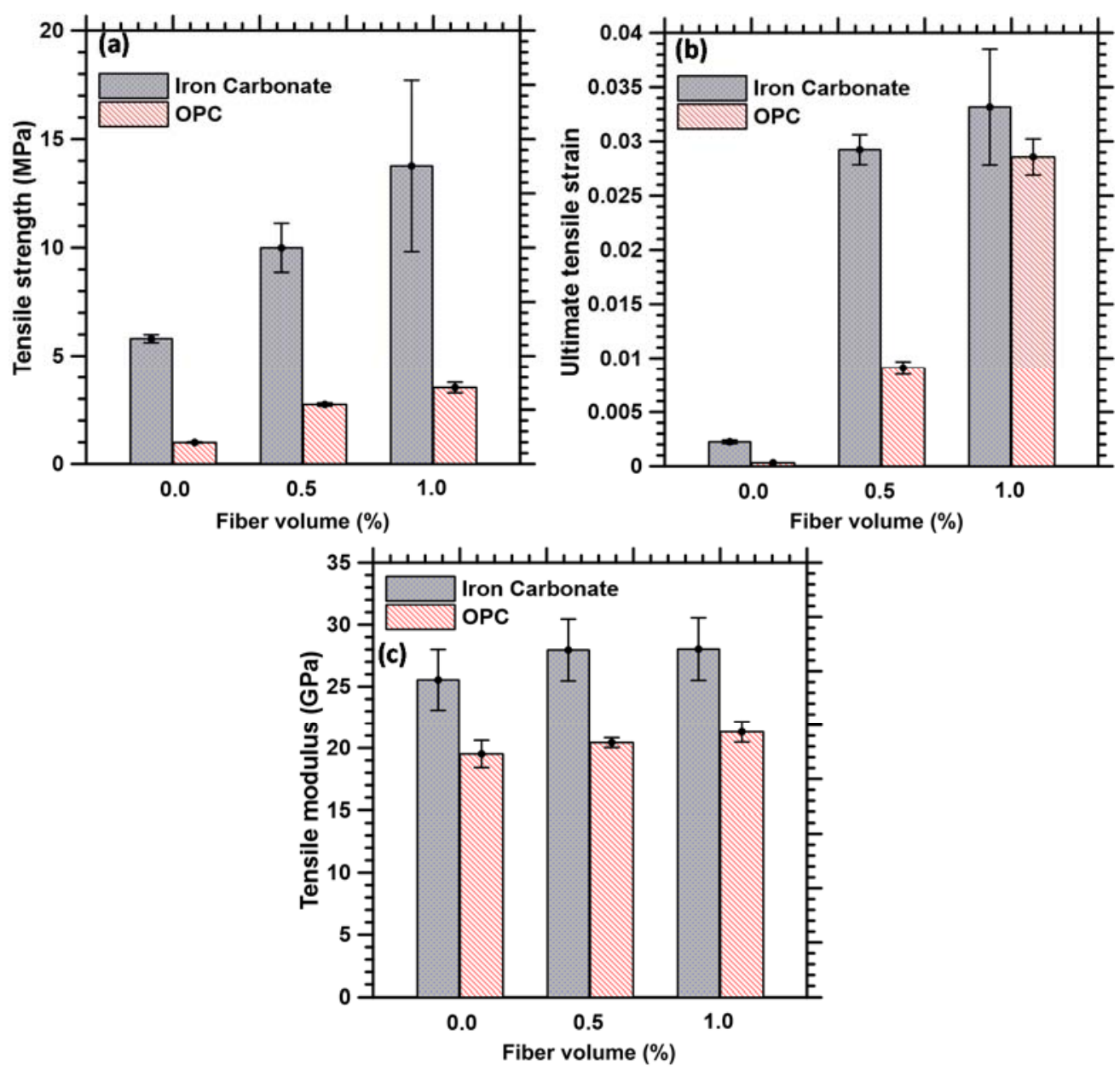

Figure 12: Comparison between OPC and iron carbonate binder (control and fiber reinforced): (a) tensile strength, (b) ultimate tensile strain and (c) tensile modulus

Figure 13 shows the stress-crack width relationship in these binder systems. The general trend suggests that the crack becomes wider beyond the peak load with a concomitant reduction in load capacity. Figure 13(a) depicts the stress-crack width relationship for the two binders in the unreinforced state. For any specific crack-width value, the iron-based binder with unreacted metallic iron particle inclusions, withstands significantly higher stress than brittle OPC. Figure 13(b) shows the stress-crack width responses for the glass fiber-reinforced binders. Incorporation of fibers improves the stress tolerance level of both the binders as expected although the iron-based fiber-reinforced systems still exhibit significantly higher stress tolerance corresponding to a given crack width due to strong matrix-glass fiber synergy [12]. 

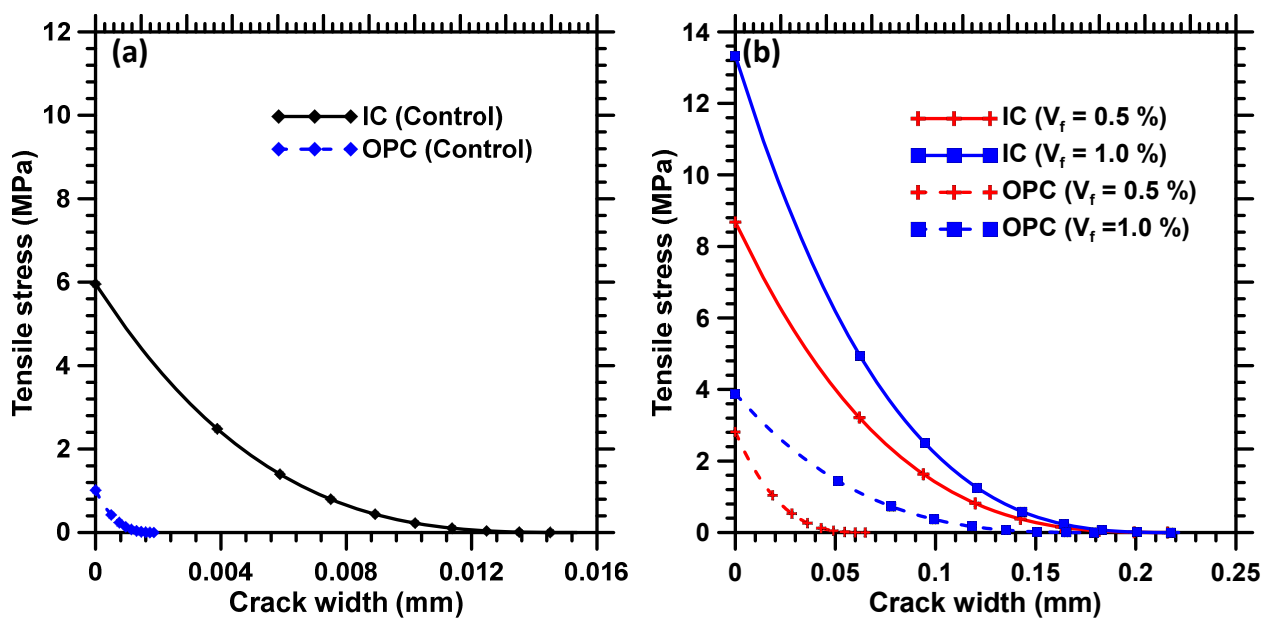

Figure 13: Stress-crack width relationships for OPC and iron carbonate binder: (a) unreinforced, and (b) fiber-reinforced composites. Note that the crack width axes scales are different.

\subsection{Correlation of back-calculated tensile parameters with fracture resistance and width of FPZ}

The relationship between the back-calculated tensile parameters, fracture resistance and FPZ width are addressed in Figures 14(a) and (b). The fracture resistance increases linearly with both the tensionsoftening area and the tensile strength. The combined effects of matrix strengthening by particulate reinforcement and post-peak modification by fibers impact the strain energy release rates. Figures 14(c) and (d) show the relationship between the FPZ width, ultimate tensile strain and inelastic component of fracture resistance for the unreinforced and fiber-reinforced systems respectively. For both unreinforced and fiber-reinforced binders, an increase in the ultimate tensile strain is also demonstrated as an increase in the width of FPZ since a significant amount of energy is dissipated through the spread of FPZ. From the perspective of fracture resistance, this is reflected as an increase in the inelastic component of fracture resistance. But a comparison between the unreinforced and fiber-reinforced binder systems reveals that fibers reduce the width of FPZ, but increase the inelastic component of fracture resistance and ultimate tensile strains. This behavior is attributed to the dominant crack-bridging mechanism of fibers which increases the strain capacity of the composite as compared to unreinforced binders and resists spread of microcracking. Although the iron particulates provide microstructural reinforcement to the matrix through angular and elongated shape resulting in significantly improved fracture response as compared to OPC, its crack-bridging capability is not as efficient as fibers with significantly higher aspect ratio, which provides further rationale into using fiber-reinforced iron carbonate composites for high performance, as has been detailed in this paper. 

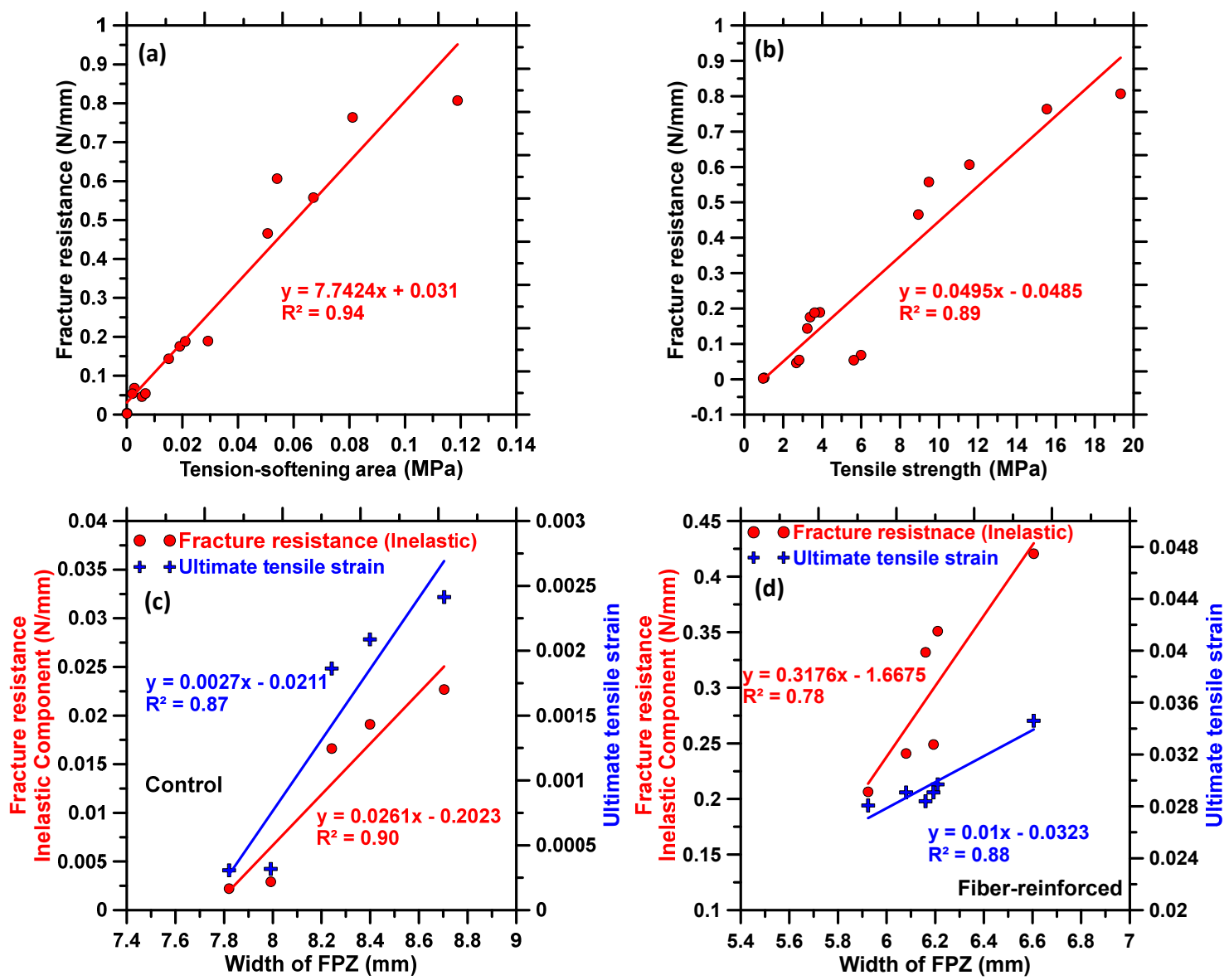

Figure 14: The fracture resistance in unreinforced and fiber reinforced binders as a function of: (a) area under softening portion of tensile stress-strain curve, and (b) tensile strength; Inelastic component of fracture resistance and ultimate tensile strain as a function of FPZ width for: (c) unreinforced, and (d) fiber-reinforced OPC and iron carbonate binders. For Figures 14(c) and (d), note that all the three axes scales are different.

\subsection{CONCLUSIONS}

This paper presents a fundamental study on the crack-propagation mechanism and the effects of fiber reinforcement in a novel iron-based binder and compares it with traditional OPC systems through characterization and evaluation of the fracture process zone (FPZ) and the correlation of its features with strain energy release rates. The fracture energies of the iron-based binder systems were found to be three to five times higher than those of the OPC binders in both the fiber-reinforced and unreinforced states.

The characterization of the region of strain localization at the tip of the notch is carried out in terms of length, width and area of the FPZ. The surface strain profiles, obtained from DIC, are utilized to locate and quantify the region of strain localization. The width and area of localized region above the notch for iron- 
based binder was consistently higher than the OPC binder in both control and fiber-reinforced states. This was attributed to the major improvement in post-peak strain capacity of the iron-based binder, quantified through inverse analysis, thereby facilitating higher amount of inelastic deformation and thus better resistance to crack-propagation. The length of FPZ remains almost same in both the binder systems although the elastic strain energy release rate, which is the resistance against incremental crack growth, was higher in iron-based systems. This behavior was attributed to dominant contribution of higher loadcarrying capacity of iron-based binders on the elastic strain energy release rate as compared to the effect of the geometric features of the FPZ. For any width of FPZ corresponding to a fixed CMOD value, the ironbased binders exhibited lower amount of crack extension and a higher flexural load capacity, signifying its superior crack tolerance. A higher elastic component of strain energy release rate contributed to the overall increase in strain energy release rate of iron-based binders containing fiber reinforcement in spite of reduction in the FPZ length.

Tensile constitutive response of the iron-based binder was back-calculated from strain energy release rates using a crack-face bridging model. The tensile strengths of control and fiber-reinforced iron-based binders were significantly higher than those of the OPC counterparts. The ultimate tensile strains and the Young's modulus values were also higher for the iron-based binder as expected. The stress-crack width relationships suggest that for any value of crack width in the deformation process during the test, the iron-based binders show significantly higher stress capacity as compared to OPC, thus reinforcing the other findings described earlier. The area under the softening portion of the tensile stress-strain curve and the tensile strengths correlate well with the total strain energy release rates. Results of this comprehensive study that include direct measurement of FPZ using DIC, experimental determination of strain energy release rates, and model-based extraction of constitutive relationship establishes the fundamental difference in crack propagation and strain localization mechanisms responsible for enhanced resistance to crack propagation of the iron-based binder.

\subsection{ACKNOWLEDGEMENTS}

The authors sincerely acknowledge the support from National Science Foundation (CMMI: 1353170 and 1463646) towards the conduct of this study. The contents of this paper reflect the views of the authors who are responsible for the facts and accuracy of the data presented herein, and do not necessarily reflect the views and policies of NSF, nor do the contents constitute a standard, specification or a regulation. We gratefully acknowledge the use of facilities within the Structural Engineering Laboratory and the Laboratory for the Science of Sustainable Infrastructural Materials (LS-SIM) at Arizona State University. 
Raw materials were provided by Schuff Steel, Iron Shell LLC, Omya AG, Headwaters Inc., and Burgess

Pigments, which are acknowledged.

\subsection{REFERENCES}

[1] Bijen J. Benefits of slag and fly ash. Constr Build Mater 1996;10:309-14.

[2] Li G, Zhao X. Properties of concrete incorporating fly ash and ground granulated blast-furnace slag. Cem Concr Compos 2003;25:293-9.

[3] Tan K, Pu X. Strengthening effects of finely ground fly ash, granulated blast furnace slag, and their combination. Cem Concr Res 1998;28:1819-25.

[4] Lothenbach B, Scrivener K, Hooton RD. Supplementary cementitious materials. Cem Concr Res 2011;41:1244-56.

[5] Zhang Z, Wang $\mathrm{H}$, Zhu Y, Reid A, Provis JL, Bullen F. Using fly ash to partially substitute metakaolin in geopolymer synthesis. Appl Clay Sci 2014;88-89:194-201.

[6] Van Jaarsveld JGS, van Deventer JSJ, Lukey GC. The effect of composition and temperature on the properties of fly ash- and kaolinite-based geopolymers. Chem Eng J 2002;89:63-73.

[7] Duxson P, Fernández-Jiménez A, Provis JL, Lukey GC, Palomo A, Deventer JSJ van. Geopolymer technology: the current state of the art. J Mater Sci 2006;42:2917-33.

[8] Wang S-D, Scrivener KL, Pratt PL. Factors affecting the strength of alkali-activated slag. Cem Concr Res 1994;24:1033-43.

[9] Wang S-D, Scrivener KL. Hydration products of alkali activated slag cement. Cem Concr Res 1995;25:561-71.

[10] Das S, Souliman B, Stone D, Neithalath N. Synthesis and Properties of a Novel Structural Binder Utilizing the Chemistry of Iron Carbonation. ACS Appl Mater Interfaces 2014;6:8295-304.

[11] Das S, Stone D, Convey D, Neithalath N. Pore- and micro-structural characterization of a novel structural binder based on iron carbonation. Mater Charact 2014;98:168-79.

[12] Das S, Hendrix A, Stone D, Mobasher B, Neithalath N. Flexural Fracture Response of a Novel Iron Carbonate Matrix - Glass Fiber Composite and its Comparison to Portland Cement-based Composites. Constr Build Mater 2015;93:360-370.

[13] Suzuki T, Sakai M. A model for crack-face bridging. Int J Fract 1994;65:329-44.

[14] Mobasher B, Bonakdar A, Bakhshi M. Back-calculation Procedure for Cyclic Flexural Fracture Tests in Fiber Reinforced Concrete. ACI Technical Report SP300-5, American Concrete Institute 2015.

[15] Chandwadkar AJ, Bhat RN, Ratnasamy P. Synthesis of iron-silicate analogs of zeolite mordenite. Zeolites 1991;11:42-7.

[16] Kumar R, Thangaraj A, Bhat RN, Ratnasamy P. Synthesis of iron-silicate analogs of zeolite beta. Zeolites 1990;10:85-9.

[17] Harder H. Synthesis of iron layer silicate minerals under natural conditions. Clays Clay Min 1978;26:65-72.

[18] Krottenthaler M, Schmid C, Schaufler J, Durst K, Göken M. A simple method for residual stress measurements in thin films by means of focused ion beam milling and digital image correlation. Surf Coat Technol 2013;215:247-52.

[19] Rossol MN, Shaw JH, Bale H, Ritchie RO, Marshall DB, Zok FW. Characterizing Weave Geometry in Textile Ceramic Composites Using Digital Image Correlation. J Am Ceram Soc 2013;96:2362-5.

[20] Yuan Y, Huang J, Peng X, Xiong C, Fang J, Yuan F. Accurate displacement measurement via a selfadaptive digital image correlation method based on a weighted ZNSSD criterion. Opt Lasers Eng 2014;52:75-85. 
[21] Ghorbani R, Matta F, Sutton MA. Full-field displacement measurement and crack mapping on masonry walls using digital image correlation. Adv. Opt. Methods Exp. Mech. Vol. 3, Springer; 2014, p. 187-96.

[22] Chen J, Zhang X, Zhan N, Hu X. Deformation measurement across crack using two-step extended digital image correlation method. Opt Lasers Eng 2010;48:1126-31.

[23] Yates JR, Zanganeh M, Tai YH. Quantifying crack tip displacement fields with DIC. Eng Fract Mech 2010;77:2063-76.

[24] Nunes LCS, Reis JML. Estimation of crack-tip-opening displacement and crack extension of glass fiber reinforced polymer mortars using digital image correlation method. Mater Des 2012;33:248-53.

[25] Das S, Aguayo M, Dey V, Kachala R, Mobasher B, Sant G, et al. The fracture response of blended formulations containing limestone powder: Evaluations using two-parameter fracture model and digital image correlation. Cem Concr Compos 2014;53:316-26.

[26] Das S, Aguayo M, Sant G, Mobasher B, Neithalath N. Fracture process zone and tensile behavior of blended binders containing limestone powder. Cem Concr Res 2015;73:51-62.

[27] Hjelmstad KD. Fundamentals of structural mechanics. Springer Science \& Business Media; 2007.

[28] Sutton MA, Orteu JJ, Schreier H. Image correlation for shape, motion and deformation measurements: basic concepts, theory and applications. Springer Science \& Business Media; 2009.

[29] Roesler J, Paulino GH, Park K, Gaedicke C. Concrete fracture prediction using bilinear softening. Cem Concr Compos 2007;29:300-12.

[30] Mobasher B. Mechanics of fiber and textile reinforced cement composites. CRC press; 2011.

[31] Wecharatana M, Shah SP. A model for predicting fracture resistance of fiber reinforced concrete. Cem Concr Res 1983;13:819-29.

[32] Skarżyński Ł, Kozicki J, Tejchman J. Application of DIC Technique to Concrete-Study on Objectivity of Measured Surface Displacements. Exp Mech 2013;53:1545-59.

[33] Skarżyński Ł, Tejchman J. Experimental Investigations of Fracture Process Using DIC in Plain and Reinforced Concrete Beams under Bending. Strain 2013;49:521-43.

[34] Shah SP. Fracture mechanics of concrete: applications of fracture mechanics to concrete, rock and other quasi-brittle materials. John Wiley \& Sons; 1995.

[35] Schapery RA. A theory of crack initiation and growth in viscoelastic media. Int J Fract 1975;11:14159. 